\title{
BMJ Open Impact of early low-calorie low-protein versus standard-calorie standard-protein feeding on outcomes of ventilated adults with shock: design and conduct of a randomised, controlled, multicentre, open-label, parallel-group trial (NUTRIREA-3)
}

To cite: Reignier J, Le Gouge A, Lascarrou J-B, et al. Impact of early low-calorie low-protein versus standard-calorie standard-protein feeding on outcomes of ventilated adults with shock: design and conduct of a randomised, controlled, multicentre, openlabel, parallel-group trial (NUTRIREA-3). BMJ Open 2021;11:e045041. doi:10.1136/ bmjopen-2020-045041

\section{- Prepublication history for} this paper is available online. To view these files, please visit the journal online (http://dx.doi. org/10.1136/bmjopen-2020045041).

Received 20 September 2020 Revised 16 March 2021 Accepted 20 April 2021

Check for updates

(C) Author(s) (or their employer(s)) 2021. Re-use permitted under CC BY-NC. No commercial re-use. See rights and permissions. Published by BMJ.

For numbered affiliations see end of article.

Correspondence to Professor Jean Reignier; jean.reignier@chu-nantes.fr

Jean Reignier (D) , ${ }^{1}$ Amélie Le Gouge, ${ }^{2}$ Jean-Baptiste Lascarrou, ${ }^{3}$ Djillali Annane (D) , ${ }^{4}$ Laurent Argaud, ${ }^{5}$ Yannick Hourmant, ${ }^{6}$ Pierre Asfar, ${ }^{7}$ Julio Badie, ${ }^{8}$ Mai-Anh Nay (1) , ${ }^{9}$ Nicolae-Vlad Botoc, ${ }^{10}$ Laurent Brisard, ${ }^{11}$ Hoang-Nam Bui, ${ }^{12}$ Delphine Chatellier, ${ }^{13}$ Louis Chauvelot, ${ }^{14}$ Alain Combes, ${ }^{15}$ Christophe Cracco, ${ }^{16}$ Michael Darmon, ${ }^{17}$ Vincent Das, ${ }^{18}$ Matthieu Debarre, ${ }^{19}$ Agathe Delbove, ${ }^{20}$ Jérôme Devaquet, ${ }^{21}$ Sebastian Voicu, ${ }^{22}$ Nadia Aissaoui-Balanant, ${ }^{23}$ Louis-Marie Dumont, ${ }^{24}$ Johanna Oziel, ${ }^{25}$ Olivier Gontier, ${ }^{26}$ Samuel Groyer, ${ }^{27}$ Bertrand Guidet, ${ }^{28}$ Samir Jaber (1) , ${ }^{29}$ Fabien Lambiotte, ${ }^{30}$ Christophe Leroy, ${ }^{31}$ Philippe Letocart, ${ }^{32}$ Benjamin Madeux, ${ }^{33}$ Julien Maizel, ${ }^{34}$ Olivier Martinet, ${ }^{35}$ Frédéric Martino, ${ }^{36}$ Emmanuelle Mercier, ${ }^{37}$ Jean-Paul Mira, ${ }^{38}$ Saad Nseir, ${ }^{39}$ Walter Picard, ${ }^{40}$ Gael Piton, ${ }^{41}$ Gaetan Plantefeve, ${ }^{42}$ Jean-Pierre Quenot, ${ }^{43}$ Anne Renault, ${ }^{44}$ Laurent Guérin,, ${ }^{45}$ Jack Richecoeur, ${ }^{46}$ Jean Philippe Rigaud, ${ }^{47}$ Francis Schneider, ${ }^{48}$ Daniel Silva, ${ }^{49}$ Michel Sirodot, ${ }^{50}$ Bertrand Souweine, ${ }^{51}$ Florian Reizine, ${ }^{52}$ Fabienne Tamion, ${ }^{53}$ Nicolas Terzi, ${ }^{54}$ Didier Thévenin, ${ }^{55}$ Guillaume Thiéry, ${ }^{56}$ Nathalie Thieulot-Rolin, ${ }^{57}$ Jean-François Timsit, ${ }^{58}$ François Tinturier, ${ }^{59}$ Patrice Tirot, ${ }^{60}$ Thierry Vanderlinden, ${ }^{61}$ Isabelle Vinatier, ${ }^{62}$ Christophe Vinsonneau, ${ }^{63}$ Diane Maugars, ${ }^{3}$ Bruno Giraudeau ${ }^{2}$

\section{ABSTRACT}

Introduction International guidelines include early nutritional support ( $\leq 48$ hour after admission), 20-25 kcal/ $\mathrm{kg} /$ day, and $1.2-2 \mathrm{~g} / \mathrm{kg} /$ day protein at the acute phase of critical illness. Recent data challenge the appropriateness of providing standard amounts of calories and protein during acute critical illness. Restricting calorie and protein intakes seemed beneficial, suggesting a role for metabolic pathways such as autophagy, a potential key mechanism in safeguarding cellular integrity, notably in the muscle, during critical illness. However, the optimal calorie and protein supply at the acute phase of severe critical illness remains unknown. NUTRIREA-3 will be the first trial to compare standard calorie and protein feeding complying with guidelines to low-calorie low-protein feeding. We hypothesised that nutritional support with calorie and protein restriction during acute critical illness decreased day 90 mortality and/or dependency on intensive care unit (ICU) management in mechanically ventilated patients receiving vasoactive amine therapy for shock, compared with standard calorie and protein targets.
Methods and analysis NUTRIREA-3 is a randomised, controlled, multicentre, open-label trial comparing two parallel groups of patients receiving invasive mechanical ventilation and vasoactive amine therapy for shock and given early nutritional support according to one of two strategies: early calorie-protein restriction ( $6 \mathrm{kcal} / \mathrm{kg} /$ day- $0.2-0.4 \mathrm{~g} / \mathrm{kg} /$ day) or standard calorie-protein targets ( $25 \mathrm{kcal} / \mathrm{kg} / \mathrm{day}, 1.0-1.3 \mathrm{~g} / \mathrm{kg} /$ day) at the acute phase defined as the first 7 days in the ICU. We will include 3044 patients in 61 French ICUs. Two primary end-points will be evaluated: day 90 mortality and time to ICU discharge readiness. The trial will be considered positive if significant between-group differences are found for one or both alternative primary endpoints. Secondary outcomes include hospital-acquired infections and nutritional, clinical and functional outcomes.

Ethics and dissemination The NUTRIREA-3 study has been approved by the appropriate ethics committee. Patients are included after informed consent. Results will be submitted for publication in peer-reviewed journals. Trial registration number NCT03573739. 


\section{INTRODUCTION}

Severe critical illness is associated during the acute phase with anorexia, metabolic disorders, endocrine dysfunction and a major catabolic response responsible for severe skeletal and diaphragmatic muscle wasting. ${ }^{1}$ Among critically ill patients requiring mechanical ventilation (MV) and catecholamines for shock, nearly $40 \%-50 \%$ die, and functional recovery is often delayed in survivors. ${ }^{2}$ Nutritional support is crucial, as malnutrition is associated with poor outcomes. Prescribing nutritional support in the critically ill is the result of a complex decision-making process designed to optimise three key parameters: the timing, the dose and the route of artificial feeding. International guidelines encourage early nutritional support ( $\leq 48$ hours after admission), via the enteral route if not contraindicated, with $20-25 \mathrm{kcal} / \mathrm{kg} /$ day, and $1.2-2 \mathrm{~g} /$ $\mathrm{kg} /$ day protein at the acute phase. ${ }^{34}$ These targets are rarely achieved in patients with severe critical illnesses, who frequently experience gastroparesis responsible for intolerance to enteral nutrition (EN). ${ }^{5}$ Observational studies have indicated that calorie and protein deficiencies were associated with nosocomial infections, intensive care unit (ICU)-acquired weakness, delayed weaning off MV, longer stays and higher mortality. ${ }^{6-12}$

However, recent data challenge the appropriateness of providing standard amounts of calories and protein during the acute phase of critical illness. ${ }^{13}{ }^{14}$ Studies showed no outcome benefits with higher intakes. ${ }^{15} 16$ Instead, adding parenteral nutrition (PN) to increase intakes was associated with longer ICU stays and more infectious complications. ${ }^{17}{ }^{18}$ Higher protein intakes during the acute phase may be associated with greater muscle wasting and ICUacquired weakness. ${ }^{119}$ Restricting calorie and protein intakes seemed beneficial, suggesting a role for metabolic pathways such as autophagy, a potential key mechanism in safeguarding cellular integrity, notably in the muscle, during critical illness. ${ }^{20} 21$ The recent EDEN and PERMIT trials showed no differences in patient outcomes between hypocaloric and standard feeding. ${ }^{22-24}$ However, in both studies, calorie intakes were below-target in the standard groups. Moreover, patients in both PERMIT trial groups received similar protein intakes, as protein solutions were added in the hypocaloric group. Last, the TARGET trial demonstrated no benefit of delivering $100 \%$ vs $70 \%$ of the recommended calorie intake on outcomes of critically ill patients. ${ }^{25}$ Thus, the optimal calorie and protein supply at the acute phase of severe critical illness remains unknown. ${ }^{146-29}$

We designed the NUTRIREA-3 trial to compare standard calorie and protein feeding complying with guidelines to low-calorie low-protein feeding in a well-defined group of severely ill ICU patients requiring at least MV and vasoactive drugs. These patients typically have poor outcomes with long ICU stays, high frequencies of ICUacquired weakness and infections, and high mortality. ${ }^{130}$ Reported impacts of nutritional support were greatest in the most severely ill ICU patients. ${ }^{34} 3132$ Our hypothesis is that, in those severe critically ill patients, low-calorie
Strengths and limitations of this study

- NUTRIREA-3 is a pragmatic randomised controlled trial whose large number of patients recruited in numerous intensive care units (ICUs) enhance the reliability and general applicability of the results.

- We included a well-defined population of very severely critically ill patients requiring at least vasoactive drugs and mechanical ventilation, at high risk for death or protracted recovery, and therefore most likely to benefit from improved early nutritional support.

- We used two strong patient-centred primary outcomes, that is, 90-day mortality and ICU dependency, and we evaluated important secondary outcomes, including long-term function, in keeping with recommendations about studies of nutritional support in critically ill patients.

- NUTRIREA-3 is the first study to evaluate the potential benefits of calorie and protein restriction versus standard calorie and protein targets during early nutritional support, using very different amounts of calories and proteins.

A limitation is that blinding of nutritional strategies is not feasible.

low-protein feeding at the early phase of critical illness improves muscle preservation, thereby improving outcomes, and most notably diminishing mortality and dependency on ICU care.

\section{METHODS AND ANALYSIS}

\section{Trial design}

NUTRIREA-3 is a randomised, controlled, multicentre, open-label trial comparing two parallel groups of patients.

\section{Participants, interventions, outcomes}

Participating units

Of the 61 French ICUs participating in the study, 34 are in university hospitals. All participating ICU staff members have attended training in the study procedures and protocols for providing nutritional support.

\section{Study population and recruitment modalities}

Inclusion criteria are age older than 18 years; invasive MV for an expected duration of at least 48 hours after inclusion, started in the ICU within the past 24 hours, or started before ICU admission with ICU admission within the 24 hours after intubation; treatment with a vasoactive agent for shock (epinephrine, dobutamine or norepinephrine); nutritional support expected to be started within 24 hours after intubation or within 24 hours after ICU admission when MV was started before ICU admission; and patient and/or next-of-kin informed about the study and having consented to participation in the study. If the patient is unable to receive information and no next-of-kin can be contacted during screening for the study, trial inclusion will be completed as an emergency procedure by the ICU physician, in compliance with French law.

Exclusion criteria are specific nutritional needs, such as pre-existing long-term home $\mathrm{EN}$ or $\mathrm{PN}$, for chronic bowel disease; dying patient, not-to-be-resuscitated order or other treatment limitation decision at ICU admission; 


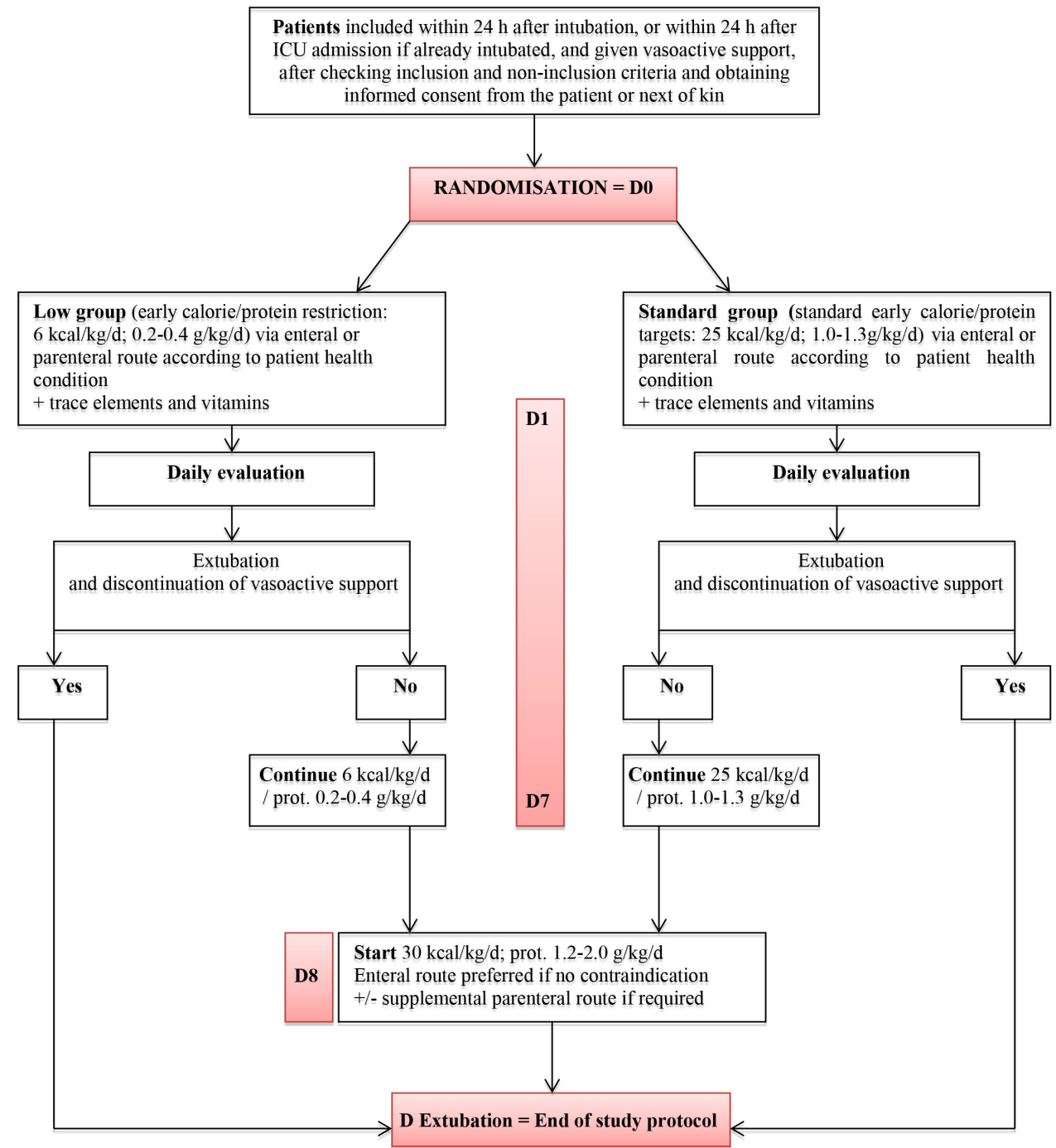

Figure 1 Study interventions. ICU, intensive care unit.

pregnancy, recent delivery or lactation; adult under guardianship; and department of corrections inmate.

\section{Interventions}

After study inclusion, patients will be allocated at random to one of two nutritional support strategies (figure 1). The designated feeding strategy will be initiated as soon as possible after randomisation (in all patients, within 24 hours after intubation or ICU admission in patients with MV started before admission) and continued until extubation and withdrawal of vasoactive support, or death, or day 7, whichever occurs first.

In the low-calorie low-protein (low) group, the calorie target will be $6 \mathrm{kcal} / \mathrm{kg} /$ day and the protein target $0.2-0.4 \mathrm{~g} / \mathrm{kg} /$ day during the acute phase, that is, from D0 to $\mathrm{D} 7$. On $\mathrm{D} 8$, the calorie target will be $30 \mathrm{kcal} / \mathrm{kg} /$ day and the protein target $1.2-2.0 \mathrm{~g} / \mathrm{kg} /$ day.

In the standard-calorie/standard-protein (Standard) group, the first-line calorie target calculated based on body weight $(\mathrm{BW})$ is $25 \mathrm{kcal} / \mathrm{kg} /$ day and the protein target $1.0-1.3 \mathrm{~g} / \mathrm{kg} /$ day during the acute phase, that is, from D0 to D7. On D8, the calorie target will be $30 \mathrm{kcal} /$ $\mathrm{kg} /$ day and the protein target $1.2-2.0 \mathrm{~g} / \mathrm{kg} /$ day.

Daily nutritional intakes needed to meet the allocated calorie target will be calculated based on BW. In obese patients (body mass index, BMI $>30 \mathrm{~kg} / \mathrm{m}^{2}$ ), the $\mathrm{BW}$ yielding a BMI of $30 \mathrm{~kg} / \mathrm{m}^{2}$ will be used. In patients with $\mathrm{BMI}<18.5 \mathrm{~kg} / \mathrm{m}^{2}$, the following corrected BW will be used: (ideal $\mathrm{BW}+$ actual BW) $/ 2$. The calorie/protein ratios of nutritional solutions currently available in French hospitals will ensure that the protein intake complies with the allocated nutritional regimen.

Nutritional support protocol

The nutritional support protocol, including measures designed to evaluate tolerance, is standardised as indicated below.

\section{General principles of nutritional support in both study arms}

Nutritional support is started as soon as possible after randomisation and no later than 24 hours after intubation or after ICU admission if intubation preceded ICU admission. 
Randomised controlled trials showed that feeding route during the acute phase had no impact on major clinical outcomes of critically ill patients when isocaloric nutrition was provided in both arms. ${ }^{33} 34$ Thus, during the acute phase, bedside physicians will be free, each day, to choose the best feeding route, according to clinical considerations, to ensure that the calorie target is achieved. After the acute phase, enteral feeding remains the preferred route in patients without contraindications. ${ }^{4}$ Thus, on day 8 , in the absence of contraindications to $\mathrm{EN}, \mathrm{PN}$ will be stopped in those patients fed via the parenteral route, and EN started. From day 8 onwards, supplemental PN may be added in the event of intolerance to EN precluding the achievement of the predefined calorie targets.

Nutritional support is prescribed as a flow rate $(\mathrm{mL} /$ hour) and started at the prescribed flow rate (as opposed to increased gradually). The feed is delivered continuously over the 24-hour cycle, with no interruptions. Actual feed delivery is monitored regularly based on the volumes delivered relative to the predefined daily calorie targets. In addition, special attention is directed to avoiding delays. Any interruption in feed delivery is reported to the ICU physician in charge. Except in special situations, nutritional support is not interrupted while transporting the patient. However, when EN or PN must be interrupted (eg, for a specific gastrointestinal or radiological investigation), the flow rate is not increased to compensate for the interruption. Finally, all patients are in the semi-recumbent supine position (torso inclined $30^{\circ}-45^{\circ}$ relative to the horizontal plane).

After extubation, regardless of time since randomisation, decisions about the continued need for, and optimal route of, nutritional support are made by the physician in charge of the patient. Patients who are reintubated within 7 days after trial inclusion are managed until the end of the acute phase according to the arm they were randomised to during the first intubation period.

\section{Enteral nutrition}

Isoosmotic isocaloric normal-protein polymeric preparations are used during the first week in both groups, after which the choice of feed is at the discretion of the physician. The feed is delivered via a 14-French silicone gastric tube. Tube position in the middle of the stomach is checked on a radiograph obtained at ICU admission or immediately after tube placement, as well as when the tube is changed or repositioned.

A predefined protocol is used to manage upper gastrointestinal intolerance to EN. This protocol was used in the NUTRIREA-2 trial. ${ }^{34}$ To minimise the risk of gastric intolerance and consequently of vomiting, the volume of supplemental water given enterally will be as small as possible during the first study week. Residual gastric volume is not monitored. ${ }^{35}$ The tolerance of $\mathrm{EN}$ is defined based only on episodes of significant vomiting or regurgitation (passage of enteral nutrition formula into the mouth, outside the mouth or into the endotracheal tube in the absence of care procedures or mobilisation).
Minimal regurgitation or vomiting triggered by tracheal aspiration or oral cavity care is not taken to indicate intolerance. EN intolerance leads to the following two measures. First, treatment with a prokinetic agent is initiated after confirmation that there are no contraindications. The study ICUs use the prokinetic agent of their choice, according to their standard practice. The prokinetic agent is discontinued when EN at the highest prescribed flow rate has been well tolerated for 48 hours. Second, if gastric intolerance persists despite prokinetic therapy, the flow rate is decreased by $25 \mathrm{~mL}$ /hour every 6 hours until the signs of intolerance resolve. Therefore, EN is stopped (and the gastric tube placed under suction) only in patients with intolerance despite a flow rate $\leq 25 \mathrm{~mL} /$ hour. All interruptions in EN delivery must be reported to the physician in charge of the patient. This precaution is particularly important in patients receiving insulin. EN is resumed at the prescribed flow rate (appropriate to the patient's needs) after 6 hours have elapsed with no further signs of intolerance. Patients at high risk for gastric intolerance, such as those turned in the prone position for acute respiratory distress syndrome, receive prophylactic prokinetic treatment starting at the first turn in the prone position. ${ }^{36} 37$

\section{Parenteral nutrition}

Ternary admixtures packaged in bags and containing the three groups of macronutrients are used according to standard practice in each participating centre. Supplemental electrolytes are supplied in a solution separate from the parenteral feed, according to the needs of each patient. PN is delivered continuously via a central venous catheter (CVC). Special attention is directed to preventing infections by complying with the standard protocols for CVC insertion and maintenance used in each of the participating centres. Proper CVC position is checked on a radiograph.

\section{Additional intakes}

Additional water, electrolytes, vitamins and trace elements are given intravenously according to the needs of each individual patient as assessed by the physician in charge and using the standard preparations and protocols available in each study ICU.

\section{Monitoring of intestinal transit}

The volume and appearance of the stools are monitored daily. The occurrence of constipation (no stool for more than 6 days) or diarrhoea (more than $300 \mathrm{~mL}$ of liquid stool or 4 loose stools per day) will be reported and will lead to the appropriate diagnostic and therapeutic management. ${ }^{153839}$ EN is not stopped for diarrhoea, which leads to the following measures. First, treatments that accelerate bowel transit, including prokinetic agents, are stopped. Second, a stool test for Clostridium difficile toxin is performed in patients receiving antibiotics. Third, the enteral solution is changed if the first measure is ineffective and the C. difficile toxin test is negative. Finally, if 
the diarrhoea persists despite the measures listed above, the rate of enteral feeding is reduced until the diarrhoea resolves then increased again gradually until the desired flow rate. ${ }^{40}$

\section{Blood glucose control}

Close monitoring and strict application of the blood glucose-control and insulin-therapy protocols used at each study centre will be ensured. Blood glucose targets will be at the discretion of each physician in charge, according to the usual practice and protocols in their ICU. In patients receiving insulin therapy, blood glucose levels will be determined at least hourly if nutritional support is discontinued or decreased (because of poor tolerance of $\mathrm{EN}$ ) for as long as the patient remains intolerant to, or off, nutrition.

\section{Study outcomes}

\section{Primary endpoints}

Two primary end-points will be analysed: all-cause mortality by day 90 , and time to readiness for ICU discharge. Information on vital status will be collected on the 90th day after patient inclusion. For discharged patients, information on this primary endpoint will be collected by a telephone call to the patient's home. The time of ICU discharge to a regular ward may be affected by the availability of beds on regular wards, which may induce bias. The study will, therefore, consider the time to readiness for ICU discharge. A patient will be considered ready for ICU discharge as soon as all predefined clinical conditions for ICU discharge are fulfilled (box 1), regardless of ward-bed availability. Readiness for ICU discharge will be checked daily in all patients weaned from invasive MV and vasoactive drugs. A similar strategy regarding this endpoint has been used previously in studies on nutrition in the ICU. ${ }^{17} 18$

The trial will be considered positive if significant between-group differences are found for one or both alternative primary endpoints.

\section{Secondary outcomes}

- Daily mean values during the first week, throughout the time on endotracheal MV and from weaning off MV to readiness for ICU discharge of the following:

\section{Box 1 Criteria for readiness for intensive care unit (ICU)} discharge

A patient will be considered ready for ICU discharge when he/she meets all of the following criteria:

- No longer in need of, or at risk for needing, invasive mechanical ventilation.

- No longer in need of, or at risk for needing, vasoactive support.

- No agitation or altered consciousness requiring close monitoring and management.

- No severe acute metabolic or haematological disorder requiring close monitoring and management.
- Number of calories (in Kcal) delivered enterally and/or parenterally.

- Ratio (as a \%) of prescribed over delivered calories.

- Proportion of patients who achieved their calorie target from day 0 to 7 .

- Daily mean values from day 0 to 7 and during MV of the following:

- Protein supply (g) given enterally and/or parenterally.

- Volume of fluids (in $\mathrm{mL}$ ) received (daily mean from day 0 to 7 and during MV).

- From day 0 to 7 :

- SOFA score changes.

- Changes in daily maximum blood glucose levels.

- Proportion of patients with hypoglycaemia.

- Total insulin dose received daily.

- Days on insulin treatment from day 0 to readiness for ICU discharge.

- Proportion of patients with at least one ICU-acquired infection; an independent blinded committee will adjudicate all ICU-acquired infections.

- Ventilator-associated pneumonia (VAP): the diagnosis of VAP is suspected based on the development or persistence of lung infiltrates on the chest radiograph with at least two of the following criteria: body temperature $\geq 38.5^{\circ} \mathrm{C}$ or $\leq 35.5^{\circ} \mathrm{C}$, leucocytosis $(>10$ $\left.000 / \mathrm{mm}^{3}\right)$ or leucopenia $\left(<4000 / \mathrm{mm}^{3}\right)$, and purulent tracheobronchial aspirate, from $\mathrm{H} 48$ after intubation to $\mathrm{H} 48$ after extubation. The diagnosis will have to be confirmed by a positive semiquantitative bacteriological test: bronchoalveolar lavage $\left(>10^{-4} \mathrm{cfu} / \mathrm{mL}\right)$, brush $\left(>10^{-3} \mathrm{cfu} / \mathrm{mL}\right)$, tracheal aspirate $\left(>10^{-6} \mathrm{cfu} /\right.$ $\mathrm{mL})$ or protected distal specimen $\left(>10^{-3} \mathrm{cfu} / \mathrm{mL}\right){ }^{41}{ }^{42}$ VAP episodes are recorded from 48 hours after intubation until day 2 after extubation.

- Proportion of patients with at least one VAP episode.

- Total number of VAP episodes in each group.

- Other ICU-acquired infections:

- Proportion of patients with at least one episode of bacteraemia.

- Proportion of patients with at least one CVC-related infection.

- Proportion of patients with at least one episode of urinary tract infection.

- Proportion of patients with at least one soft tissue infection.

- Proportion of patients with other nosocomial infections.

- Descriptive bacteriological data: organisms recovered in the overall population with nosocomial infections and antimicrobial resistance profiles.

- Proportion of patients with at least one episode of liver dysfunction, defined as serum bilirubin $>50 \mu \mathrm{moL} / \mathrm{L}$ and/or elevation $>3 \mathrm{~N}$ of one or more liver enzymes $(\gamma$-glutamyltransferase, alkaline phosphatase and ASAT-ALAT) at the end of MV, on day 7 (in patients on MV for more than 7 days), and at ICU discharge. 
- Proportion of patients with at least one episode of vomiting or regurgitation while on MV.

- Proportion of patients with at least one episode of diarrhoea defined as liquid stools in a volume greater than $300 \mathrm{~mL} / 24$ hours in patients with a faecal collector or as more than four loose stools/24 hours. ${ }^{15}$

- Proportion of patients with at least one episode of constipation (no stool for more than 6 days).

- Proportion of patients with at least one documented episode of bowel ischaemia defined as absent blood flow in one of the main arteries supplying the bowel (superior mesenteric artery, inferior mesenteric artery or coeliac artery) with evidence of bowel wall compromise on an imaging study (CT angiography, angiograph, or MR angiography) or presence of criteria for colonic ischaemia according to the Favier classification system (stage I, petechiae; stage II, petechiae and superficial ulcers; and stage III, necrotic ulcers and polypoid lesions) by endoscopy (rectosigmoidoscopy or colonoscopy). ${ }^{43}$

- Mean changes in serum albumin, prealbumin and C reactive protein measured at baseline, at the end of MV, on day 7 (in patients on MV for more than 7 days) and at ICU discharge.

- Changes in mean BW determined at baseline, on day 7 , and at ICU discharge.

- Days on MV.

- Hospital stay length (days in hospital).

- ICU mortality, 28-day mortality and hospital mortality.

- Proportions of patients mobilised from day 0 to 7 and total number of active mobilisations, using predetermined criteria ${ }^{44}$ (box 2).

- Total Medical Research Council (MRC) score and proportion of patients with ICU-acquired paresis at the time of readiness for ICU discharge ${ }^{4546}$; the MRC score can range from 0 (quadriplegia) to 60 (normal muscle strength); scores $<48$ will define ICU-acquired paresis.

- Proportion of patients with at least one criterion for persistent altered health status at the time of readiness

\section{Box 2 Mobilisation scale}

Remains in bed
No mobilisation.
Rurned in bed.
Sitting position in bed with the head of the bed elevated.
Mobilised in the bed
Passive mobilisation of the legs in bed.
Active mobilisation of the legs in bed.
Mobcling motions in bed.
Milised out of bed
Sits on the edge of the bed with the feet on the floor.
Stands.
Marches in place.

for ICU discharge, among the following: tracheostomy, non-invasive ventilation, ongoing renal-replacement therapy, PN, EN via a nasogastric tube; Glasgow Coma Scale score $<15$ and treatment-limitation decision. ${ }^{47}$

- SF-36 (Short-Form 36) score completed during a phone call to the patient by an independent blinded research nurse or psychologist 3 months and 1 year after study inclusion. ${ }^{48} 49$

\section{Organisation of the trial}

Figure 2 is the study diagram.

\section{Recruitment modalities}

All patients treated with invasive MV and vasopressor support for shock within 24 hours after intubation, or within 24 hours after ICU admission if already intubated, will be screened for eligibility by the ICU physicians and clinical research nurses, around the clock and 7 days a week. Patients will be included after checking inclusion and non-inclusion criteria. A log of patients considered for study participation will be kept and will include any reasons for non-inclusion and refusals of consent.

\section{Randomisation}

Randomisation is centralised and performed using a secure, computer-generated, interactive, web-response system available at each study centre. Randomisation is stratified on study centre with a 1:1 ratio.

\section{Blinding}

The trial will be open, since the nature of the intervention precludes blinding of healthcare staff to group assignment. However, the absence of blinding cannot have an impact on either of the primary endpoints. Day 90 mortality is an objective endpoint with no evidence that absence of blinding may affect the data. ${ }^{50}$ Given its more subjective nature, the primary endpoint of readiness to discharge alive from the ICU will be checked daily by the bedside physician according to predefined criteria, in order to strongly limit the risk of detection bias. Moreover, the secondary endpoints relevant to nosocomial infections will be validated by an adjudication committee.

\section{Sample size}

Assuming a $43 \%$ day 90 mortality rate in the standard group and a $5 \%$ absolute decrease in day 90 mortality (to $38 \%)$ in the low group, with the alpha risk set at $4.9 \%$ (as two interim analyses are planned) and the beta risk at 20\%, 1522 patients are needed in each group, that is, a theoretical total of 3044 patients.

This sample size will provide $94 \%$ power to detect a 1.5-day difference in time to ICU discharge alive between the two groups (mean, 14.5 days in the control group vs 13.0 days in the experimental group).

No corrections will be made for multiple comparisons. Indeed, adjusting for multiplicity is controversial and there is no consensus about the appropriate analysis. ${ }^{51}$ Moreover, adjusting for multiplicity may lead to increased sample size and subsequent decreased feasibility of the 


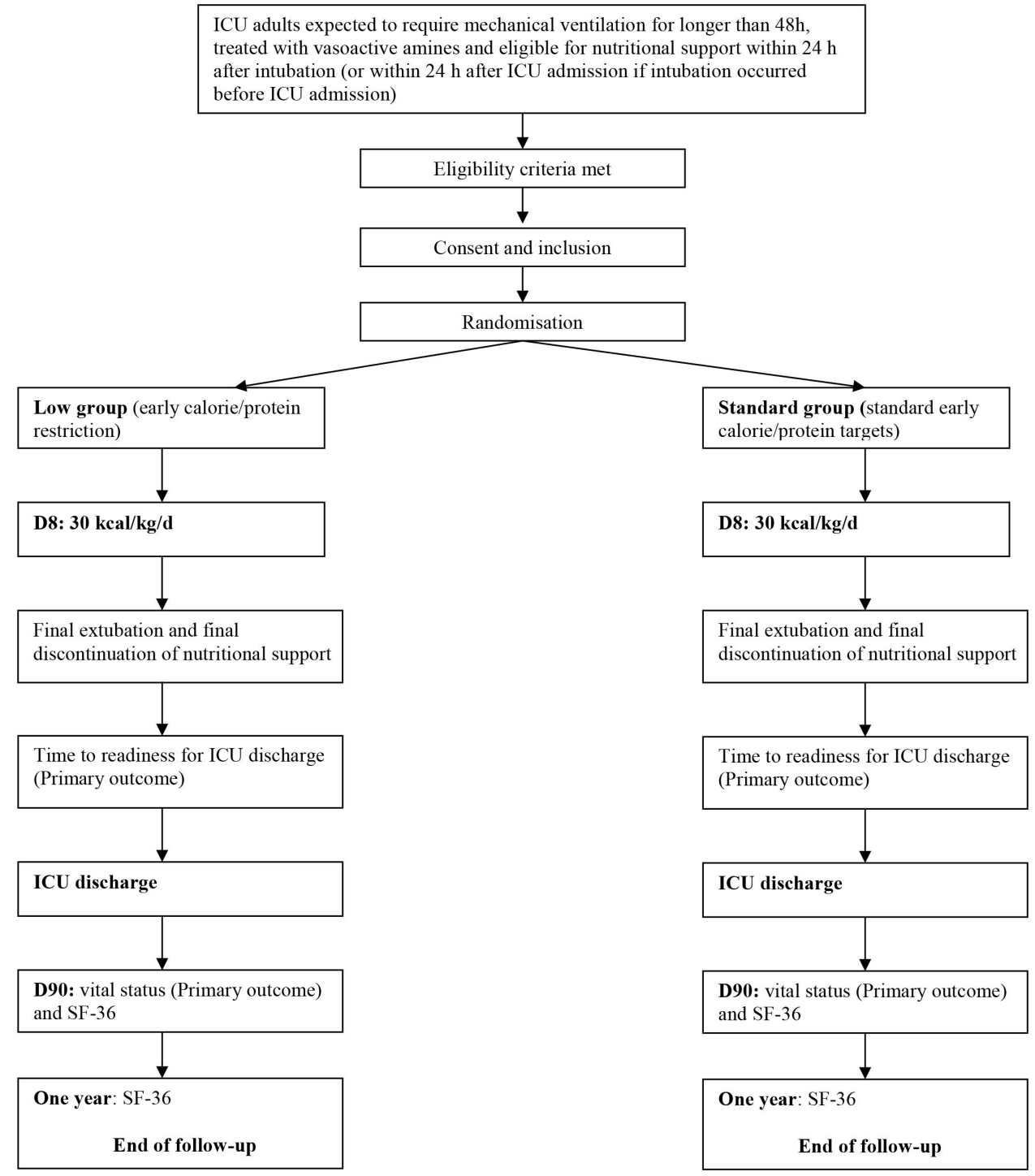

Figure 2 Study diagram. ICU, intensive care unit.

study. Last, most recent studies with a similar design did not use corrections for multiple comparisons. ${ }^{17} 18$

The ICU stay lengths in survivors and mortality rates used for the sample size estimation are those obtained in the NUTRIREA-1 and NUTRIREA-2 trials, which used similar inclusion criteria.

\section{Interim analysis}

Given the need for a large sample size, two interim analyses will be scheduled, one after enrolment of 1000 patients and the other after enrolment of 2000 patients. Members of the independent data safety monitoring board (DSMB) will not be otherwise involved in the trial. This DSMB consists of one methodologist and two intensivists. For both interim analyses, the DSMB will have access to unblinded results on day-90 mortality, time to discharge alive from the ICU, variations in SOFA (Sequential Organ Failure Assessment) scores from day 0 to 7 , amounts of calories and proteins received daily from day 0 to 7 and nosocomial infections. The results of the interim analyses will not be disclosed unless they lead the DSMB to request premature trial discontinuation.

\section{Statistical analysis}

Each patient will remain in the group assigned by randomisation, regardless of subsequent events. A statistical analysis report will be written to describe all the findings, according to Consolidated Standards of Reporting Trials (CONSORT) Statement recommendations, while taking into account the specific features of the trial, most notably the nonpharmacological nature of the intervention. The baseline features of the groups established by randomisation will be compared using descriptive statistics; no statistical tests will be performed.

\section{Primary endpoint}

Day 90 mortality will be reported as the point estimate with the $95 \%$ CI in each group. The difference in proportions with the $95 \%$ CI will also be estimated. Day 90 mortality will be compared between the two groups using the $\chi^{2}$ test. 
Table 1 Study flow chart of patient follow-up

\begin{tabular}{|c|c|c|c|c|c|c|c|c|}
\hline & Inclusion & DO* & D1 to Dn & $\begin{array}{l}\text { End of study } \\
\text { protocol }\end{array}$ & $\begin{array}{l}\text { Ready for ICU } \\
\text { discharge }\end{array}$ & Day 28 & Day 90 & $\begin{array}{l}\text { 1-year end of } \\
\text { follow-upt }\end{array}$ \\
\hline $\begin{array}{l}\text { Eligibility: check inclusion and exclusion } \\
\text { criteria }\end{array}$ & $x$ & & & & & & & \\
\hline Randomisation & & $x$ & & & & & & \\
\hline Demographic characteristics & & $x$ & & & & & & \\
\hline Weight & & $x$ & $x$ & & & & & \\
\hline Ventilation & & $x$ & $x$ & & & & & \\
\hline Laboratory tests & & $\mathrm{x}$ & $X^{*}$ & & & & & \\
\hline SOFA & & $x$ & $x$ & & & & & \\
\hline Nutritional evaluation & & $x$ & $x$ & & & & & \\
\hline Nosocomial infections & & & $x$ & & & & & \\
\hline Final extubation & & & & $x$ & & & & \\
\hline Final discontinuation of nutritional support & & & & $x$ & & & & \\
\hline Health status & & & & & $x$ & & & \\
\hline MRC score & & & & & $x$ & & & \\
\hline Survived/died & & & & & $x$ & $x$ & $x$ & $x$ \\
\hline SF-36 & & & & & & & $\mathrm{x}$ & $x$ \\
\hline
\end{tabular}

${ }^{*}$ From time of inclusion to 23:59 hour.

†Information will be collected by phone contact with patients or relatives.

ICU, intensive care unit; MRC, Medical Research Council.

Time to readiness for ICU discharge will be analysed using the competing risk approach (Fine and Gray model), with death in the ICU as a competing risk.

\section{Secondary endpoints}

The incidence of patients with at least one nosocomial infection will be estimated and compared between the groups using a Fine and Gray model, with death and ICU discharge alive as competing events. The incidence of patients with at least one VAP episode will be estimated using a Fine and Gray model, with not only death as a competing risk, but also time to extubation +2 days, since after this point any episode of pneumonia would not be classified as VAP. For CVC-related infections, the competing risks will be death and CVC removal; for urinary tract infections they will be death and urinary catheter removal. Bacteraemia, soft tissue infections and other infections will be analysed using the same method as for the pooled nosocomial infections. For descriptive bacteriological data (organisms recovered with their resistance profiles for each nosocomial infection), only descriptive analyses will be performed. For the proportions of patients with at least one episode of vomiting or regurgitation, diarrhoea, constipation, documented acute colonic pseudo-obstruction, documented bowel ischaemia, mechanical complication of CVC insertion, hypoglycaemia from day 0 to 7 and liver dysfunction, the method will be the same as for nosocomial infections. Changes over time in delivered calories and proteins will be represented graphically by boxplots created each day on the same graph; changes over time will be compared between the two groups using a mixed linear model, after data transformation if necessary. The same analysis will be performed for volume of feeds delivered each day. The proportion of patients who achieved $100 \%$ of their daily calorie target will be determined at each follow-up time point (in days) and compared between the two groups using a logistic random-effects model. Day 28 mortality will be analysed in the same way as day 90 mortality. For ICU and hospital mortality rates, a Fine and Gray model will be used, with ICU discharge and hospital discharge as events competing with death during the stay. Time to extubation will be analysed using a Fine and Gray model with death and ICU discharge as competing events. Changes over time in SOFA, total insulin, blood glucose, nutritional markers and $\mathrm{BW}$ will be analysed using the method described above for the number of calories delivered. For the proportion of mobilised patients, patients with at least one criterion of persistent altered health status at the time of readiness for ICU discharge, and patients with ICU-acquired paresis, the method will be the same as for nosocomial infections. The MRC sum score at the time of readiness for ICU discharge and days on insulin will be compared between the two groups 
using the non-parametric Wilcoxon test. The total quality-oflife SF-36 score will be compared between the two groups using a mixed linear model.

\section{Data collection and follow-up}

The following data will be recorded until the patient is extubated: demographic and clinical data, nutrition monitoring data, treatments given, laboratory tests, invasive devices, functional evaluation and data relevant to nosocomial infections. The patient will be followed up for 1 year after study inclusion; at hospital discharge, on day 28 and day 90 and at 1 year, the vital status will be recorded. The SF-36 score will be recorded on day 90 and 1 year after study inclusion. Table 1 is the study flow chart.

\section{Data entry and monitoring}

An internet-based data collection tool will be used for this study to store the data of all the participants. This electronic case report form (eCRF) is a secure, interactive, web response system available at each study centre. It is provided and managed by the biometrical unit of the Tours University Hospital (CIC INSERM 1415, Tours, France). Access to the eCRF will require only an Internet connection and a browser.

Monitoring of the data collected and of the screening forms in each participating centre will be carried out by the Research Division, Promotion Department, of the Nantes University hospital. Research assistants will regularly perform on-site checks of adherence to the protocol and accuracy of recorded data.

\section{Trial status}

Inclusions started in July 2018. The scheduled interim analysis were performed on the first 1000 (by October 2009) and 2000 (by March 2020) included patients, respectively. Both analyses led the DSMB to recommend continuation of the study. Recruitment in the trial was interrupted from March to June 2020 because of the COVID-19 crisis, when all ICUs were full with COVID-19 patients and all research teams were working only on COVID-19 trials. By 19 August 2020, 2764 patients had been included. Recruitment was completed in December 2020.

\section{ETHICS AND DISSEMINATION}

\section{Ethical review board}

The NUTRIREA-3 trial was approved by the competent French authorities on 20 April 2016 (Comité de Protection des Personnes Sud-Méditerranée 2, registration 2018-A00424-51).

\section{Consent}

The patients are included after providing their signed informed consent to trial participation. For patients unable to consent because of impaired consciousness or severe critical illness, information about the study is provided to their next of kin. Patients who are unable to consent and for whom no relative is available to consent to study participation within a time frame compatible with the study design are included after completion of an emergency consent form by the bedside physician. The relatives are informed of the inclusion as soon as possible. Patients are asked to confirm their willingness to participate in the trial once they regain decision-making capacity. Data of patients without relatives who die without previously recovering consciousness will be included in the statistical analysis.

\section{Confidentiality and source data archiving}

The medical data about each patient will be communicated only to the institution (ie, the sponsor) with which the chief investigator is affiliated or to a person appointed by the chief investigator and the sponsor under conditions that ensure the confidentiality of the patient data. During or at completion of the study, the data collected from the study participants and communicated by the individuals involved in the study will be rendered anonymous. Study investigators will archive all study data for at least 15 years after the end of the study.

\section{Dissemination policy}

The publication policy will comply with international recommendations (N Engl J Med, 1997; 336:309-315) and the CONSORT statement (http://www.consort-statement.org). Findings will be published in peer-reviewed journals and presented during national and international scientific meetings. Communications and scientific reports relevant to this study will be under the responsibility of the study coordinator (JR), who will obtain the approval of the other investigators.

\section{Patient and public involvement}

Neither patients nor the public are involved in the study.

\section{Author affiliations}

${ }^{1}$ Médecine Intensive Réanimation, Centre Hospitalier Universitaire de Nantes, Nantes, France

${ }^{2}$ INSERM CIC 1415, Centre Hospitalier Regional Universitaire de Tours, Tours, France ${ }^{3}$ Service de Médecine Intensive Réanimation, Centre Hospitalier Universitaire de Nantes, Nantes, France

${ }^{4}$ Service de Médecine Intensive Réanimation, Hôpital Raymond Poincaré, Garches, France

${ }^{5}$ Service de Médecine Intensive Réanimation, Centre Hospitalier Universitaire de Lyon, Lyon, France

${ }^{6}$ Pôle Anesthésie Réanimations, Service d'Anesthésie Réanimation Chirurgicale, CHU Nantes, Nantes, France

${ }^{7}$ Service de Médecine Intensive Réanimation, Centre Hospitalier Universitaire d'Angers, Angers, France

${ }^{8}$ Service de Médecine Intensive Réanimation, Hôpital Nord Franche-Comté, Montbeliard, France

${ }^{9}$ Service de Médecine Intensive Réanimation, Centre Hospitalier Régional d'Orleans Hôpital de La Source, Orleans, France

${ }^{10}$ Service de Médecine Intensive Réanimation, Centre Hospitalier de Saint-Malo, Saint-Malo, France

${ }^{11}$ Service d'Anesthésie Réanimation Chirurgicale, CHU Nantes, Nantes, France

${ }^{12}$ Service de Médecine Intensive Réanimation, CHU de Bordeaux, Bordeaux, France

${ }^{13}$ Service de Médecine Intensive Réanimation, CHU Poitiers, Poitiers, France

${ }^{14}$ Service de Médecine Intensive Réanimation, CHU Lyon, Lyon, France

${ }^{15}$ Service de Médecine Intensive Réanimation, Hôpital Universitaire Pitié Salpêtrière, Paris, France

${ }^{16}$ Service de Médecine Intensive Réanimation, Centre Hospitalier d'Angouleme, Angouleme, France 
${ }^{17}$ Service de Médecine Intensive Réanimation, Hôpital Saint-Louis, Paris, France

${ }^{18}$ Médecine Intensive Réanimation, CHI André Grégoire, Montreuil, France

${ }^{19}$ Médecine Intensive Réanimation, Centre Hospitalier de Saint Brieuc, Saint Brieuc, France

${ }^{20}$ Réanimation Polyvalente, Centre Hospitalier Bretagne Atlantique, Vannes, France

${ }^{21}$ Medical-Surgical Intensive Care Unit, Hôpital Foch, Suresnes, France

${ }^{22}$ Médecine Intensive Réanimation, Hopital Lariboisiere, Paris, France

${ }^{23}$ Médecine Intensive Réanimation, Hôpital Europeen Georges-Pompidou -

Broussais, Paris, France

${ }^{24}$ Service de Médecine Intensive Réanimation, Hôpital Louis-Mourier, Colombes, France

${ }^{25}$ Service de Médecine Intensive Réanimation, Hôpital Avicenne, Bobigny, France

${ }^{26}$ Service de Médecine Intensive Réanimation, Centre Hospitalier de Chartres,

Chartres, France

${ }^{27}$ Service de Médecine Intensive Réanimation, Centre Hospitalier de Montauban, Montauban, France

${ }^{28}$ Service de Médecine Intensive Réanimation, Hôpital Saint-Antoine, Paris, France

${ }^{29}$ Service de Réanimation Chirurgicale, Hôpital Saint-Eloi, Montpellier, France

${ }^{30}$ Service de Médecine Intensive Réanimation, Centre Hospitalier de Valenciennes,

Valenciennes, France

${ }^{31}$ Service de Médecine Intensive Réanimation, Centre Hospitalier Emile Roux, Le

Puy en Velay, France

${ }^{32}$ Service de Médecine Intensive Réanimation, Centre Hospitalier de Rodez, Rodez, France

${ }^{33}$ Service de Médecine Intensive Réanimation, Centre Hospitalier de Bigorre, Tarbes, France

${ }^{34}$ Service de Médecine Intensive Réanimation, Centre Hospitalier Universitaire

Amiens-Picardie, Amiens, France

${ }^{35}$ Service de Médecine Intensive Réanimation, Centre Hospitalier Universitaire de La Réunion, Saint-Denis, France

${ }^{36}$ Service de Médecine Intensive Réanimation, Centre Hospitalier Universitaire Pointe-à-Pitre Abymes, Pointe-a-Pitre, Guadeloupe

${ }^{37}$ Service de Médecine Intensive Réanimation, Centre Hospitalier Régional Universitaire de Tours, Tours, France

${ }^{38}$ Service de Médecine Intensive Réanimation, Hôpital Cochin, Paris, France

${ }^{39}$ Service de Médecine Intensive Réanimation, CHU Lille, Lille, France

${ }^{40}$ Service de Médecine Intensive Réanimation, Centre Hospitalier de Pau, Pau, France

${ }^{41}$ Service de Médecine Intensive Réanimation, Centre Hospitalier Universitaire de Besancon, Besancon, France

${ }^{42}$ Service de Médecine Intensive Réanimation, Centre Hospitalier d'Argenteuil, Argenteuil, France

${ }^{43}$ Service de Médecine Intensive Réanimation, Centre Hospitalier Universitaire de

Dijon, Dijon, France

${ }^{44}$ Service de Médecine Intensive Réanimation, CHRU de Brest, Brest, France

${ }^{45}$ Service de Médecine Intensive Réanimation, Centre Hospitalier Universitaire de

Bicêtre, Le Kremlin-Bicetre, France

${ }^{46}$ Service de Médecine Intensive Réanimation, Centre Hospitalier de Beauvais,

Beauvais, France

${ }^{47}$ Service de Médecine Intensive Réanimation, Centre Hospitalier de Dieppe, Dieppe, France

${ }^{48}$ Service de Médecine Intensive Réanimation, Hopitaux Universitaires de

Strasbourg, Strasbourg, France

${ }^{49}$ Service de Médecine Intensive Réanimation, Centre Hospitalier de Saint Denis,

Saint Denis, France

${ }^{50}$ Service de Médecine Intensive Réanimation, Centre Hospitalier Annecy Genevois,

Epagny Metz-Tessy, France

${ }^{51}$ Service de Médecine Intensive Réanimation, Centre Hospitalier Universitaire de Clermont-Ferrand, Clermont-Ferrand, France

${ }^{52}$ Service de Médecine Intensive et Réanimation, Centre Hospitalier Universitaire de Rennes, Rennes, France

${ }^{53}$ Service de Médecine Intensive Réanimation, Centre Hospitalier Universitaire de Rouen, Rouen, France

${ }^{54}$ Service de Médecine Intensive Réanimation, Centre Hospitalier Universitaire

Grenoble Alpes Hopital Michallon, La Tronche, France

${ }^{55}$ Service de Médecine Intensive Réanimation, Centre Hospitalier de Lens, Lens, France

${ }^{56}$ Service de Médecine Intensive Réanimation, Centre Hospitalier Universitaire de Saint-Etienne, Saint-Etienne, France
${ }^{57}$ Service de Médecine Intensive Réanimation, Centre Hospitalier de Melun, Melun, France

${ }^{58}$ Service de Médecine Intensive Réanimation, Hôpital Bichat - Claude-Bernard, Paris, France

${ }^{59}$ Réanimation Chirurgicale, Centre Hospitalier Universitaire Amiens-Picardie, Amiens, France

${ }^{60}$ Service de Médecine Intensive Réanimation, Centre Hospitalier du Mans, Le Mans, France

${ }^{61}$ Service de Médecine Intensive Réanimation, Institut Catholique de Lille, Lille, France

${ }^{62}$ Service de Médecine Intensive Réanimation, Centre Hospitalier Départemental Vendée, La Roche-sur-Yon, France

${ }^{63}$ Service de Médecine Intensive Réanimation, Centre Hospitalier de Béthune, Bethune, France

Acknowledgements We are indebted to Antoinette Wolfe, MD, for assistance in preparing and reviewing the manuscript; Carine Coffre and Frédérique Musset for managing the database; Manon Rouaud for coordinating the study; and Professor Sylvie Chevret (Biostatistics and Medical Information Department, Hôpital Saint-Louis, Paris, France; Centre de Recherche en Épidémiologie et Statistiques (CRESS-INSERM-UMR1153), Paris, France; Epidemiology and Clinical Statistics for Tumour, Respiratory, and Resuscitation Assessments (ECSTRRA) Team, Paris, France; Université de Paris, Paris, France), Professor Jean Chastre (Medical ICU, La Pitié-Salpêtrière Hospital, Paris, France), and Professor Pierre-François Laterre (St Luc University Hospital, Université Catholique de Louvain, Brussels, Belgium) for constituting the independent data safety and monitoring board.

Contributors ALG and JR prepared the first draft of the manuscript. JR, J-BL, $D M, A L G$ and $B G$ wrote the manuscript. JR, J-BL, ALG, DM and BG participated in designing the NUTRIREA-3 study. ALG and BG wrote the statistical analysis plan and performed the sample size estimation. JR and DM obtaining funding for the study. JR, J-BL, DA, LAA, YH, PA, JB, M-AN, N-VB, LB, H-NB, DC, LC, AC, CC, MD, VD, MD, $A D, J D, S V, N A-B, L-M D, J 0, O G$, SG, BG, SJ, FL, CL, PL, BM, JM, OM, FM, EM, J-PM, SN, WP, GPi, GPI, J-PQ, AR, LG, JR, JPR, FS, DS, MS, BS, FR, FT, NT, DT, GT, NT-R, J-FT, FT, PT, TV, IV and CV contributed to acquire the study data. All authors revised the manuscript for important intellectual content and read and approved the final version of the manuscript.

Funding The NUTRIREA-3 trial is sponsored by the Nantes University Hospital (CHU, Nantes, France) and supported by a grant from the French Ministry of Health (Programme Hospitalier de Recherche Clinique, PHRC 2017-0213) that will cover all expenses related to the research. The NUTRIREA-3 trial does not require funding from, or any other form of participation of, any pharmaceutical company.

Competing interests JR had travel and accommodation expenses to attend scientific meetings covered by Baxter and Fresenius.

Patient and public involvement Patients and/or the public were not involved in the design, or conduct, or reporting, or dissemination plans of this research.

Patient consent for publication Not required.

Provenance and peer review Not commissioned; externally peer reviewed.

Open access This is an open access article distributed in accordance with the Creative Commons Attribution Non Commercial (CC BY-NC 4.0) license, which permits others to distribute, remix, adapt, build upon this work non-commercially, and license their derivative works on different terms, provided the original work is properly cited, appropriate credit is given, any changes made indicated, and the use is non-commercial. See: http://creativecommons.org/licenses/by-nc/4.0/.

\section{ORCID iDs}

Jean Reignier http://orcid.org/0000-0002-3768-3496

Djillali Annane http://orcid.org/0000-0001-6805-8944

Mai-Anh Nay http://orcid.org/0000-0002-6116-4987

Samir Jaber http://orcid.org/0000-0002-7257-8069

\section{REFERENCES}

1 Puthucheary ZA, Rawal J, McPhail M, et al. Acute skeletal muscle wasting in critical illness. JAMA 2013;310:1591-600.

2 Hermans G, Van den Berghe G. Clinical review: intensive care unit acquired weakness. Crit Care 2015;19:274.

3 Singer P, Blaser AR, Berger MM, et al. ESPEN guideline on clinical nutrition in the intensive care unit. Clin Nutr 2019;38:48-79. 
4 Taylor BE, McClave SA, Martindale RG. Guidelines for the provision and assessment of nutrition support therapy in the adult critically ill patient: Society of critical care medicine (SCCM) and American Society for Parenteral and Enteral Nutrition (ASPEN). Crit Care Med 2016;44:390-438.

5 Blaser AR, Starkopf J, Kirsimägi Ü, et al. Definition, prevalence, and outcome of feeding intolerance in intensive care: a systematic review and meta-analysis. Acta Anaesthesiol Scand 2014;58:914-22.

6 Alberda C, Gramlich L, Jones N, et al. The relationship between nutritional intake and clinical outcomes in critically ill patients: results of an international multicenter observational study. Intensive Care Med 2009;35:1728-37.

7 Elke G, Wang M, Weiler N, et al. Close to recommended caloric and protein intake by enteral nutrition is associated with better clinical outcome of critically ill septic patients: secondary analysis of a large international nutrition database. Crit Care 2014;18:R29.

8 Compher C, Chittams J, Sammarco T, et al. Greater protein and energy intake may be associated with improved mortality in higher risk critically ill patients: a multicenter, multinational observational study. Crit Care Med 2017;45:156-63.

9 Allingstrup MJ, Esmailzadeh N, Wilkens Knudsen A, et al. Provision of protein and energy in relation to measured requirements in intensive care patients. Clin Nutr 2012;31:462-8.

10 Faisy C, Candela Llerena M, Savalle M, et al. Early ICU energy deficit is a risk factor for Staphylococcus aureus ventilator-associated pneumonia. Chest 2011;140:1254-60.

11 Villet S, Chiolero RL, Bollmann MD, et al. Negative impact of hypocaloric feeding and energy balance on clinical outcome in ICU patients. Clin Nutr 2005;24:502-9.

12 Wei X, Day AG, Ouellette-Kuntz H, et al. The association between nutritional adequacy and long-term outcomes in critically ill patients requiring prolonged mechanical ventilation: a multicenter cohort study. Crit Care Med 2015;43:1569-79.

13 Casaer MP, Van den Berghe G. Nutrition in the acute phase of critical illness. N Engl J Med 2014;370:1227-36.

14 Preiser J-C, van Zanten ARH, Berger MM, et al. Metabolic and nutritional support of critically ill patients: consensus and controversies. Crit Care 2015;19:35.

15 Doig GS, Simpson F, Finfer S, et al. Effect of evidence-based feeding guidelines on mortality of critically ill adults: a cluster randomized controlled trial. JAMA 2008;300:2731-41.

16 Heyland DK, Murch L, Cahill N, et al. Enhanced protein-energy provision via the enteral route feeding protocol in critically ill patients: results of a cluster randomized trial. Crit Care Med 2013;41:2743-53.

17 Fivez T, Kerklaan D, Mesotten D, et al. Early versus late parenteral nutrition in critically ill children. N Engl J Med 2016;374:1111-22.

18 Casaer MP, Mesotten D, Hermans G, et al. Early versus late parenteral nutrition in critically ill adults. $N$ Engl $\mathrm{J}$ Med 2011;365:506-17.

19 Casaer MP, Wilmer A, Hermans G, et al. Role of disease and macronutrient dose in the randomized controlled EPaNIC trial: a post hoc analysis. Am J Respir Crit Care Med 2013;187:247-55.

20 Vanhorebeek I, Gunst J, Derde S, et al. Insufficient activation of autophagy allows cellular damage to accumulate in critically ill patients. J Clin Endocrinol Metab 2011;96:E633-45.

21 Choi AMK, Ryter SW, Levine B. Autophagy in human health and disease. N Engl J Med 2013;368:651-62.

22 Arabi YM, Aldawood AS, Haddad SH, et al. Permissive underfeeding or standard enteral feeding in critically ill adults. N Engl J Med 2015;372:2398-408.

23 Needham DM, Dinglas VD, Bienvenu OJ, et al. One year outcomes in patients with acute lung injury randomised to initial trophic or full enteral feeding: prospective follow-up of EDEN randomised trial. BMJ 2013;346:f1532.

24 National Heart, Lung, and Blood Institute Acute Respiratory Distress Syndrome (ARDS) Clinical Trials Network, Rice TW, Wheeler AP, et al. Initial trophic vs full enteral feeding in patients with acute lung injury: the EDEN randomized trial. JAMA 2012;307:795-803.

25 Deane AM, Little L, Bellomo R, et al. Outcomes Six Months after Delivering $100 \%$ or $70 \%$ of Enteral Calorie Requirements during Critical Illness (TARGET). A Randomized Controlled Trial. Am J Respir Crit Care Med 2020;201:814-22.

26 Marik PE, Hooper MH. Normocaloric versus hypocaloric feeding on the outcomes of ICU patients: a systematic review and metaanalysis. Intensive Care Med 2016;42:316-23.

27 Marik PE, Rice TW. Feeding the critically ill: more questions than answers! Am J Respir Crit Care Med 2017;195:555-6.
28 Preiser J-C. High protein intake during the early phase of critical illness: yes or no? Crit Care 2018;22:261.

29 Singer P, Cohen J. Nutrition in the ICU: proof of the pudding is in the tasting. Intensive Care Med 2015;41:154-6.

30 Iwashyna TJ, Ely EW, Smith DM, et al. Long-term cognitive impairment and functional disability among survivors of severe sepsis. JAMA 2010;304:1787-94.

31 Rhodes A, Evans LE, Alhazzani W, et al. Surviving sepsis campaign: international guidelines for management of sepsis and septic shock: 2016. Intensive Care Med 2017;43:304-77.

32 Artinian V, Krayem H, DiGiovine B. Effects of early enteral feeding on the outcome of critically ill mechanically ventilated medical patients. Chest 2006;129:960-7.

33 Harvey SE, Parrott F, Harrison DA, et al. Trial of the route of early nutritional support in critically ill adults. N Engl $J$ Med 2014;371:1673-84.

34 Reignier J, Boisramé-Helms J, Brisard L, et al. Enteral versus parenteral early nutrition in ventilated adults with shock: a randomised, controlled, multicentre, open-label, parallel-group study (NUTRIREA-2). Lancet 2018;391:133-43.

35 Reignier J, Mercier E, Le Gouge A, et al. Effect of not monitoring residual gastric volume on risk of ventilator-associated pneumonia in adults receiving mechanical ventilation and early enteral feeding: a randomized controlled trial. JAMA 2013;309:249-56.

36 Poulard F, Dimet J, Martin-Lefevre L, et al. Impact of not measuring residual gastric volume in mechanically ventilated patients receiving early enteral feeding: a prospective before-after study. JPEN J Parenter Enteral Nutr 2010;34:125-30.

37 Reignier J, Dimet J, Martin-Lefevre L, et al. Before-after study of a standardized ICU protocol for early enteral feeding in patients turned in the prone position. Clin Nutr 2010;29:210-6.

38 Gacouin A, Camus C, Gros A, et al. Constipation in long-term ventilated patients: associated factors and impact on intensive care unit outcomes. Crit Care Med 2010;38:1933-8.

39 van der Spoel JI, Schultz MJ, van der Voort PHJ, et al. Influence of severity of illness, medication and selective decontamination on defecation. Intensive Care Med 2006;32:875-80.

40 Brisard L, Le Gouge A, Lascarrou J-B, et al. Impact of early enteral versus parenteral nutrition on mortality in patients requiring mechanical ventilation and catecholamines: study protocol for a randomized controlled trial (NUTRIREA-2). Trials 2014;15:507.

41 Chastre J, Fagon J-Y. Ventilator-associated pneumonia. Am J Respir Crit Care Med 2002;165:867-903.

42 Hubmayr RD, Burchardi H, Elliot M, et al. Statement of the 4th International Consensus Conference in Critical Care on ICUAcquired Pneumonia-Chicago, Illinois, May 2002. Intensive Care Med 2002;28:1521-36.

43 Favier C, Bonneau HP, Tran Minh V. [Endoscopic diagnosis of regressive ischemic colitis. Endoscopic, histologic and arteriographic correlations]. Nouv Presse Med 1976;5:77-9.

44 Wright SE, Thomas K, Watson G, et al. Intensive versus standard physical rehabilitation therapy in the critically ill (EPICC): a multicentre, parallel-group, randomised controlled trial. Thorax 2018;73:213-21.

45 Bittner EA, Martyn JA, George E, et al. Measurement of muscle strength in the intensive care unit. Crit Care Med 2009;37:S321-30.

46 Sharshar T, Bastuji-Garin S, Stevens RD, et al. Presence and severity of intensive care unit-acquired paresis at time of awakening are associated with increased intensive care unit and hospital mortality. Crit Care Med 2009;37:3047-53.

47 Santamaria JD, Duke GJ, Pilcher DV, et al. The timing of discharge from the intensive care unit and subsequent mortality. A prospective, multicenter study. Am J Respir Crit Care Med 2015;191:1033-9.

48 Kosinski M, Gande B, Ware J. SF-36® health survey manual \& interpretation guide. Lincoln, RI: Quality Metric Incorporated, 2005.

49 Oeyen SG, Vandijck DM, Benoit DD, et al. Quality of life after intensive care: a systematic review of the literature. Crit Care Med 2010;38:2386-400.

50 Anthon CT, Granholm A, Perner A, et al. No firm evidence that lack of blinding affects estimates of mortality in randomized clinical trials of intensive care interventions: a systematic review and meta-analysis. $J$ Clin Epidemiol 2018;100:71-81.

51 Li G, Taljaard M, Van den Heuvel ER, et al. An introduction to multiplicity issues in clinical trials: the what, why, when and how. Int $J$ Epidemiol 2017;46:746-55. 